\title{
GEOSSISTEMAS E GESTÃO AMBIENTAL NA BACIA HIDROGRÁFICA DO RIO SÃO JOÃO-RJ
}

\author{
SANDRA BAPTISTA DA CUNHA ${ }^{1}$ \\ Departamento de Geografia Universidade Federal Fluminense \\ Marcos Welausen Dias de Freitas ${ }^{2}$
}

\section{Introdução}

A abordagem complexa e integradora das relações entre a natureza e a sociedade é fundamental para a realização de práticas eficientes de gestão ambiental com caráter holístico. Tal abordagem é a base da corrente científica que procura alterar os pressupostos da ciência tradicional racionalista e reducionista, trazendo noções inter e transdisciplinares como sistemas complexos, auto-organização e outros.

No campo da Geografia, o estudo integrado do ambiente e suas variáveis físicas, ecológicas e sociais ocupou, desde os primórdios, a análise da paisagem. A noção de geossistemas, original da escola russa, procura aplicar os métodos sistêmicos no estudo da paisagem, trazendo repercussões em outras escolas geográficas como a brasileira.

A caracterização dos geossistemas da bacia do rio São João-RJ (figura 1) teve como base teórica tais contribuições integradoras, tendo buscado as interações da problemática ambiental e sendo relacionada diretamente com o planejamento e gestão ambientais da área de estudo.

A bacia hidrográfica do rio São João-RJ, recentemente transformada em Área de Proteção Ambiental pelo poder público federal (APA Bacia do Rio São João/ Mico-leão-dourado, decreto de 26/06/2002), localiza-se no Estado do Rio de Janeiro, Sudeste brasileiro, entre as coordenadas de $22^{\circ} 20^{\prime}$ e $22^{\circ} 50^{\prime} \mathrm{S}$ de latitude

\footnotetext{
${ }^{1}$ Falta rodapé

${ }^{2}$ Falta rodapé
} 
e de $42^{\circ} 00^{\prime}$ e $42^{\circ} 40^{\prime} \mathrm{W}$ de longitude. Apresenta cerca de $2.113 \mathrm{~km}^{2}$ de área, em forma de pêra, englobando oito municípios: Silva Jardim (43,52\%), Casimiro de Abreu (16,30\%), Araruama (16,26\%), Rio Bonito (11,94\%), Cabo Frio $(8,7 \%)$, Cachoeiras de Macacu (2,46\%), Rio das Ostras $(0,44 \%)$ e São Pedro da Aldeia $(0,44 \%)$. Tem população estimada em torno de 100 mil habitantes, 60 mil em áreas urbanas e 40 mil em áreas rurais, segundo dados de 1997 (COSTA, 1999).

\section{Complexidade, Gestão Ambiental e Desenvolvimento Sustentável}

A busca por um modo de pensar diferente do paradigma científico dominante clássico é uma das principais tônicas do movimento que procura uma ciência nova após os abusos sociais e ecológicos do desenvolvimento do capitalismo no século $\mathrm{XX}$. O paradigma newtoniano-cartesiano fundamentado nos princípios do racionalismo, mecanicismo, reducionismo e o ideal da especialização, foi um dos principais motores do avanço do sistema capitalista, tanto em nível tecnológico quanto na ideologia de progresso, inerentes ao capitalismo. Uma das principais características deste paradigma dominante é a separação entre o sujeito e o objeto, traduzido na dicotomia entre a natureza e a sociedade, e com consequiências visíveis nos sinais de saturação dos limites ecológicos da biosfera.

Os estudos da complexidade preocupam-se com uma abordagem anti-reducionista, buscando uma concepção holística de caráter transdisciplinar aplicável a sistemas caóticos e complexos longe da estabilidade. Trata-se de uma corrente científica com representantes nos mais diversos campos da ciência que se baseia nos últimos avanços da ciência em áreas como a Física Quântica, a Biologia Molecular, a Cibernética e a Informática, a Matemática de base fractal, entre outras tantas contribuições das mais diversas áreas. (NUSSENZVEIG, 1999)

A partir dos anos de 1960 e 70, os estudos da complexidade assumem um grande desenvolvimento, principalmente na análise de sistemas caóticos e complexos, da auto-organização e das redes componentes e caracterizadoras dos sistemas. A primeira descrição de sistemas auto-organizadores ou complexos vem de Prigogine e Stengers (1991) com a teoria das estruturas dissipativas, interessada no comportamento auto-organizado de sistemas termodinâmicos não-lineares. Maturana e Varela (2001) desenvolveram um estudo a respeito da cognição e da auto-organização em organismos vivos, chegando à teoria da autopoiese. A tese deste novo campo científico que suscitou mais críticas e resistências foi a "hipótese de Gaia" de Lovelock (1997), que considera a Terra como um organismo vivo auto-regulado e com seus elementos estritamente inter-relacionados.

No campo epistemológico, Morin (2002) tenta restabelecer a ciência dos cortes e separações realizados pelo reducionismo clássico através de um método complexo, preocupado com as interações, interdependências e interconectividades entre os elementos físicos, biológicos e antropossociais. Feyerabend (1989) funda o anarquismo metodológico, com a única regra metodológica de que vale tudo, con- 
trapondo-se à procura de um método único de investigação da realidade, típico da ciência clássica, que não responde à complexidade do meio.

Tais estudos da complexidade são contemporâneos e acompanhados diretamente do estabelecimento do movimento ambientalista, crítico direto da degradação ambiental promovida pelo desenvolvimento do sistema capitalista. A idéia de desenvolvimento sustentável é acompanhada pela preocupação com a gestão ambiental, sendo fundamental realçar a ligação existente entre desenvolvimento sustentável, gestão ambiental e os estudos da complexidade. (FREITAS, CUNHA, 2002)

Entre os diversos exemplos desta conjugação entre o pensamento complexo e a busca de novas relações entre o homem e a natureza, cabe ressaltar a crítica à noção de progresso das sociedades capitalistas. Morin e Kern (1995) percebem a transformação da "Terra-Pátria" como o estabelecimento de uma noção de desenvolvimento não relacionada à expansão da cultura ocidental e seu ideal de progresso, sendo fundamental uma visão integrada de homem, técnica e natureza.

Capra (2003) assinala dois caminhos para atingir a sustentabilidade, o primeiro seria a alfabetização ecológica, compreensão dos princípios de organização que os ecossistemas desenvolveram para sustentar a vida; e o segundo caminho seria o projeto ecológico, que é a aplicação dos princípios de organização dos sistemas vivos na reformulação fundamental das tecnologias e das instituições sociais.

Ab'Saber (2003) ressalta o caráter de herança de processos fisiográficos e ecológicos que as paisagens assumem, sendo fundamental a compreensão destes processos para um̃a intervenção humana eficaz e sustentável. A alternativa é a conscientização da responsabilidade de todos frente às heranças paisagísticas e a busca de um modelo equilibrado entre o ecologismo utópico, que pretende preservar a natureza na forma de reservas naturais ou paraísos ambientais, e o economismo suicida, que busca a pura exploração da natureza enquanto recurso.

Monteiro (1987) analisa a geografia nos trópicos e a sua situação sócio-ambiental extremamente complexa, agravada pela condição de exploração e dependência frente às nações mais poderosas do sistema capitalista mundial, indicando formas de uso apropriadas às condições ecológicas tropicais, já conhecidas pelos habitantes originais e suas populações remanescentes. Tais formas só poderão ser amplamente utilizadas com transformações amplas e complexas que ultrapassam o domínio econômico-político e passam por uma guinada de direção rumo ao pensamento complexo, holístico e ecológico.

\section{Fisiologia da Paisagem e Geossistemas}

A Geografia tem sua formação diretamente relacionada com a busca de uma visão integrada entre a natureza e a sociedade, com os mais variados exemplos nas escolas geográficas tradicionais da Alemanha (Humboldt e a influência romântica 
da Natur Philosophie), da França (Reclus e Sorre, com o uso de métodos ecológicos de análise) e da Rússia (diversas contribuições da Ciência da Paisagem, como Vernadsky e suas noções de biosfera e noosfera). (FREITAS, 2004; FREITAS, CUNHA, 2003)

A Geografia muda de papel após o fim da $2^{\mathrm{a}}$ Guerra Mundial, relacionando-se com o planejamento territorial e passando a discutir a adequação adjetiva de aplicada ou aplicável. A partir dos anos sessenta, diversas correntes novas surgem, animadas por concepções de outros ramos da ciência, como a Cibernética, a Teoria Geral dos Sistemas, a Física Quântica, e outros. (MONTEIRO, 2001a)

Uma das principais escolas dessa renovação é a escola teorético-quantitativa, de origem anglo-americana, que foi influenciada diretamente pela Teoria Geral dos Sistemas e pela Cibernética, com os exemplos de Chorley (1971) e Schumm e Lichty (1973). Tais autores buscam uma abordagem relacionada com as idéias de sistemas abertos, fluxos de matéria e de energia, e de equilíbrio dinâmico (HACK, 1972).

As escolas da Ecologia da Paisagem e dos Geossistemas evoluíram em diversos países, como na URSS, França e Alemanha Oriental e Ocidental (onde passa a ser chamada de geoecologia), por diversos autores que buscavam as relações entre os elementos da paisagem sob uma perspectiva sistêmica e ecológica.

$\mathrm{Na}$ Geografia russa, Sochava criou a concepção de geossistemas, unidades espaciais integrando os aspectos físicos, ecológicos e sociais da paisagem, com uma dinâmica relacionada aos fluxos termodinâmicos de matéria e energia. Apresentam uma hierarquia estrutural que vai do nível planetário, ao regional e ao nível topológico, estando divididos entre geômeros (que apresentam uma estrutura homogênea) e geócoros (com estruturas diferenciadas) em relação de interdependência. Entre as unidades principais dos geômeros são os geomas (de nível regional), as fácies e a unidade elementar (biogeocenose, equivalente à ecossistema elementar). Entre os geócoros, propõe várias diferenciações escalares de microgeócoros até zonas físico-geográficas regionais. (SOCHAVA, 1978; ROUGERIE; BEROUTCHACHVILI, 1991)

Bertrand (1972) procurou adaptar a metodologia russa de geossistemas ao caso francês, estabelecendo o geossistema, geofácies e geótopos como unidades inferiores taxonômicas, estando "[...] na $4^{\mathrm{a}}, 5^{\mathrm{a}}$ ou $6^{\mathrm{a}}$ grandezas temporo-espaciais de Tricart e Cailleux (1956), escala esta mais compatível com a humana, em que a dinâmica desses geossistemas, modificada ou não, poderia expressar a dinâmica social." (RODRIGUES, 2001, p.74). Tais geossistemas seriam formados pelo potencial ecológico (a combinação de fatores físicos), pela exploração biológica (combinação dos fatores bióticos) e pela ação antrópica, apresentando uma dinâmica integrada e relacionada diretamente aos processos de biostasia e resistasia, conforme descritos por Erhart $(1962,1966)$.

$\mathrm{O}$ estudo integrado do meio ambiente no Brasil tem diferentes contribuições como as de Christofoletti (2002), Ab'Sáber (1969) e Monteiro (2001b) que buscam adequar teorias e influências do exterior à análise da realidade geográfica bra- 
sileira. Outras contribuições vêm de Casseti (1991), mesclando a análise geomorfológica e o marxismo, e de Cunha e Guerra (2000) que salientam a importância da bacia hidrográfica como elemento básico para uma análise ambiental de cunho holístico, entre outras.

Christofoletti (2002), quanto à concepção de geossistemas, equipara-os a sistemas ambientais físicos, de características abertas e representadas por complexos paisagísticos, completando sua noção de sistema ambiental físico com a importância das variáveis sociais no entendimento dos mesmos e da relação entre o estudo integrado dos geossistemas e a problemática ambiental ao nível do planejamento e gestão ambientais.

Ab'Sáber (1969) desenvolve uma metodologia aos estudos geomorfológicos sobre o Quaternário composta de três partes integradas: a compartimentação topográfica, a estrutura superficial e a fisiologia da paisagem. A fisiologia da paisagem, parte fundamental da pesquisa que pressupõe as duas primeiras, procura desenvolver um entendimento da funcionalidade ou organização da paisagem através do conhecimento interligado dos elementos físicos, ecológicos e sociais, e de sua dinâmica global.

Monteiro (2001b, 2001c) analisa a busca da noção de geossistemas como um conceito integrador da relação homem-natureza na Geografia, as possibilidades do uso da categoria para avaliações de qualidade ambiental e na aplicação da Geografia ao planejamento. Para tal, preferiu adaptar a concepção de hólon (KOESTLER, 1981), conceito de cunho holístico e complexo, nos estudos geossistêmicos, caracterizando os geossistemas como sistemas singulares complexos, representando estruturas intermediárias na ordem hierárquica. Outra questão fundamental é a preocupação com a modelização dos ritmos e da dinâmica processual dos geossistemas. Em relação à metodologia científica dos geossistemas, posiciona-se favoravelmente ao anarquismo metodológico de Feyerabend (1989) em relação ao posicionamento da ciência normal e dos paradigmas de Kuhn (1989) no debate epistemológico recente.

Tal posicionamento de Monteiro (2001b) sintetiza a importância da liberdade disciplinar e de concepções científicas necessárias para o estudo dos geossistemas. Nenhuma concepção determinista ou unilateral será capaz de apreender a realidade dos geossistemas, sendo sempre necessário um enfoque relativista e livre que permita ligações entre a ciência, a cultura e a arte em sua aplicação metodológica.

\section{Metodologia}

A metodologia empregada para o estudo dos geossistemas da bacia hidrográfica do rio São João foi caracterizada pelo enfoque interdisciplinar, buscou as relações complexas entre as variáveis ambientais físicas, ecológicas e sociais. Para tal, rêalizou-se de forma conjugada: trabalhos de campo na área; avaliação e confecção de 
documentos cartográficos, tendo por base cartográfica cartas 1:50.000 do IBGE, imagens de satélite Landsat TM (anos de 1996 e 2000) e mapas temáticos da área de estudo produzidos por Cunha (1995).

\section{Unidades Geossistêmicas}

A análise das variáveis ambientais físicas, ecológicas e sociais responsáveis pela fisiologia da paisagem e dos geossistemas da bacia do rio São João foi integrada a partir da visão de "hólons", definidos como "[...] entidades auto-reguladoras que manifestam tanto as independentes propriedades dos todos como as dependentes propriedades das partes" (KOESTLER, 1981, p.48). Tal conceito foi usado por Monteiro (2001 b) na aplicação do método geossistêmico, com o sentido de estruturas intermediárias na organização hierárquica da dinâmica espacial das áreas de estudo. Ainda, segundo Monteiro (1991) estes subsistemas apresentam caráter vertical e horizontal, representando a idéia de "arborescência", conferindo à análise geográfica estruturas e organização hierárquica, em termos de ligações, no plano vertical, e entrelaçamentos, no plano horizontal (MONTEIRO, 1991).

Os hólons verticais seriam o tronco da "arborescência" vista acima, constituída pelos níveis hierárquicos componentes do geossistema e apresentando uma dinâmica espacial escalar complexa, onde as diferentes escalas assumem interações complexas e interdependentes entre si. Tais níveis são, em ordem, o Geossistema Global (Gaia), o nível continental ou do território nacional brasileiro (Domínio Neotropical), o domínio morfoclimático de mares de morros (de cunho regional), e a bacia hidrográfica em questão.

A análise da bacia hidrográfica do rio São João possibilitou a compartimentação espacial deste nível hierárquico do geossistema planetário em cinco hólons horizontais ou unidades geossistêmicas que representariam os entrelaçamentos no plano horizontal da "arborescência" holárquica, onde deve ser ressaltada a ligação dessas estruturas ou componentes espaciais com dinâmicas locais, regionais e globais em seus processos de formação e em sua dinâmica atual, conforme a relação entre os hólons verticais apresentada.

A compartimentação espacial seguiu critérios que buscam a identificação e agrupamento do comportamento das variáveis ambientais, destacando os processos morfodinâmicos da paisagem de origem natural (geologia, geomorfologia, clima, hidrologia e ecossistemas) e antrópica (baseada na ocupação sócio-histórica). Tal agrupamento envolve um caráter complexo, devido às faixas de transição existentes entre os diferentes padrões paisagísticos. As unidades foram denominadas conforme as características morfológicas e topográficas, ou ainda de acordo com características ambientais marcantes; sendo divididas em hólons serrano, de planalto dissecado, de colinas arredondadas, aluvial e litorãneo. (figura 1) 


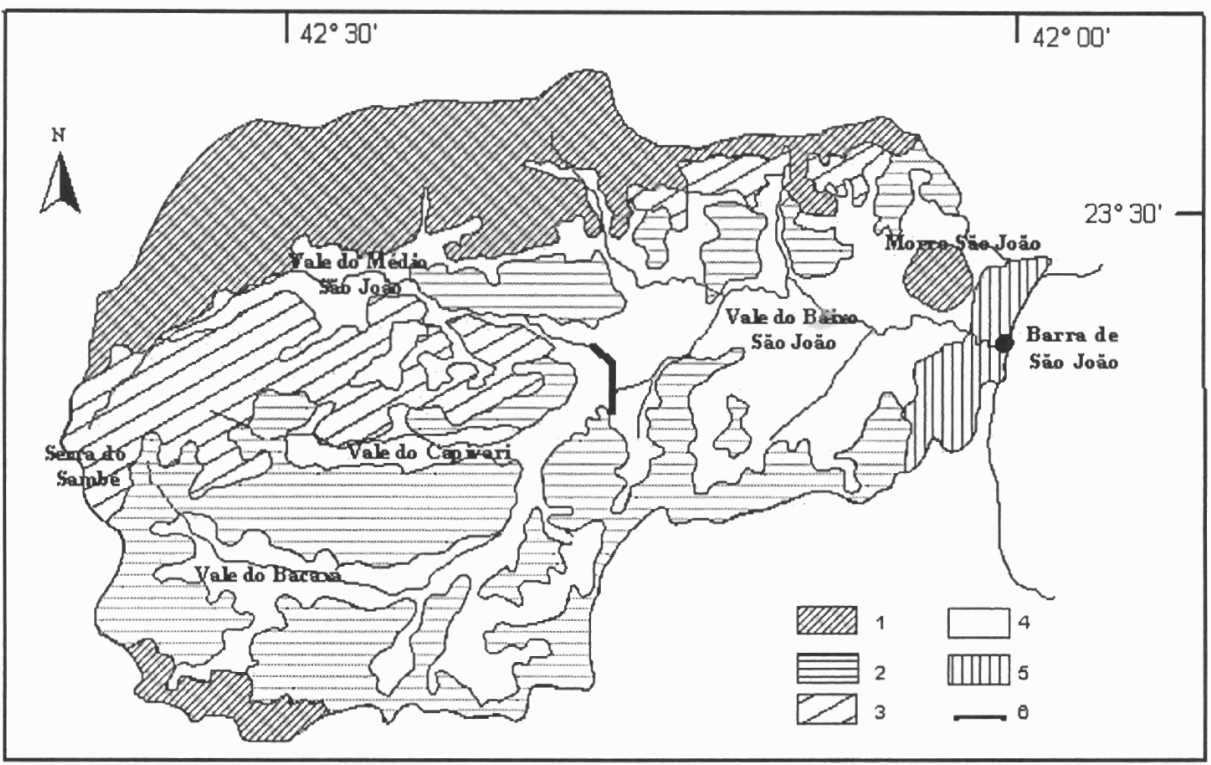

Figura 1: Unidades geossistêmicas da bacia do rio São João. I: hólon I; II: hólon II; III: hólon III; IV: hólon IV; V: hólon V. (Mapa realizado a partir de mapas temáticos de Cunha, 1995)

\section{Hólon I}

Unidade geossistêmica que domina os alto divisores da bacia hidrográfica do rio São João correspondendo ao ambiente de serra e à zona de erosão das nascentes (figura 2). Apresenta-se em maior parte no N-NW da bacia, com um setor no SW e outro à E, o Morro de São João.

As características climáticas estão diretamente relacionadas à topografia acidentada e de direção concordante com a linha de costa, responsável por chuvas orográficas durante todo o ano, com precipitações médias acima de $2300 \mathrm{~mm}$.

A base geológica deste setor, como a da maioria da bacia hidrográfica, compõem-se de unidades metamórficas e unidades intrusivas alcalinas. As primeiras são denominadas de Complexo do Litoral Fluminense, do Pré-Cambriano Inferior, com uma grande variedade litológica de gnaisses facoidais que passam a verdadeiros granitos porfiróides grosseiros; e do Grupo Serra dos Órgãos, do PréCâmbriano Médio a Superior, constituído de migmatitos associados a gnaisses e a gnaisses granitóides, com fraturamentos de direções divergentes. As unidades intrusivas alcalinas são datadas entre o Cretáceo Superior e o Terciário e se localizam a E, no Morro de São João e a W, na Serra do Sambê, de idade variável entre o Cretácio Superior e o Terciário e constituindo maciços sieníticos com brechas magmáticas e afetados por sistemas de fraturas. 
A geomorfologia é representada pela unidade de relevo montanhoso e acidentado que inclui os altos divisores N e NW, o setor SW, e o Morro de São João a W. A unidade de relevo montanhoso apresenta amplitudes altimétricas elevadas (entre 100 e $1800 \mathrm{~m}$ ) com múltiplas e sucessivas superfícies de aplainamento relacionadas às variações climáticas e do nível dos mares do quaternário. Tem encostas em regra abruptas e íngremes, de forma retilínea a convexa, com topos em crista e ricas em rupturas de declive; na baixa encosta apresentam depósitos de tálus. Os vales principais e secundários, à esquerda do rio São João são numerosos, simétricos e encaixados; com a presença de blocos retrabalhados de antigos deslizamentos e matacões e seixos (predominância de gnaisses), ao fundo dos leitos fluviais. Apresenta grande dissecação topográfica em consequiência das grandes alterações na rocha oriundas de processos morfogenéticos ligados ao escoamento superficial e ao escoamento concentrado, facilitados pela alta potencialidade erosiva apresentada devido às características climáticas desta unidade. O padrão da rede de drenagem segue a orientação da estrutura geológica, com os rios acompanhando as direções principais (NE-SW) e secundárias (NW-SE) dos dobramentos pré-cambrianos; predominando o tipo sub-dentrítico a retangular que reflete a influência exercida pelas falhas e diáclases.

O ecossistema principal deste hólon é característico do bioma Mata Atlântica, comportando-se como um ecossistema muito complexo e rico em biodiversidade, com formação ligada aos processos fisiográficos e ecológicos bio-resistáticos movidos por mudanças climáticas do Quaternário. Os principais processos em sua formação são processos biostáticos de pedogênese e de auto-adubação do solo da floresta pela ação do lençol difuso (AB’SÁBER, 1966); aliados aos processos ecológicos de sucessão natural, que correspondem à evolução da vegetação em relação à ocupação do terreno sucessivamente por diferentes comunidades vegetais, desde as comunidades pioneiras, passando por diversos estágios serais, e chegando no estágio clímax de equilíbrio dinâmico (WEAVER; CLEMENTS, 1950).

Devido aos gradientes de temperatura e umidade, em função do relevo e da altitude, a vegetação da Mata Atlântica subdivide-se em dois tipos: Floresta Pluvial Atlântica montana e baixo-montana. O primeiro tipo encontra-se nas altitudes mais elevadas, entre 800 e $1700 \mathrm{~m}$, com árvores de média de altura entre 20 e $30 \mathrm{~m}$ e podendo chegar até $230 \mathrm{~cm}$ de diãmetro, abrigando espécies de caráter ombrófilo como o palmito (Euterpe edulis), diversas canelas e outras. O segundo reveste as altitudes entre 300 e $800 \mathrm{~m}$ com variações, com a estrutura e composição variando conforme as condições ambientais, apresenta as árvores da abóbada florestal alcançando $12-25 \mathrm{~m}$ de altura, com 40-60 cm de diâmetro, com menor densidade e número de epífitas, samambaiuçus, grandes ervas e palmeiras. Entre as principais características encontradas nessas vegetações estão a grande diversidade, singularidade e o grande endemismo. A fauna da Mata Atlântica se compõem de diversas espécies de mamíferos como gambás, canídeos como os cachorros do mato, felinos 
como o gato do mato, aves como o macuco, serpentes como a jibóia, e borboletas azuis na fauna entomológica. (RIZZINI et alli, 1991; CUNHA, 1995)

A Mata Atlântica teve uma importância fundamental para os principais grupos indígenas que habitavam a região na chegada dos portugueses: os Tupinambás, de origem tupi-guarani, e os Tapuias, do domínio linguístico Macro-jê. Utilizavam-se de seus recursos principalmente nas atividades coletoras de caça e pesca e o uso do solo em clareiras abertas na mata para atividades agrícolas de subsistência, vivendo de forma harmoniosa com a natureza, respeitando os limites de autosustentabilidade do ecossistema. Estas comunidades e suas populações tradicionais sofreram um processo de extinção provocada pelas armas e doenças do conquistador europeu, estando quase extintas sócio-culturalmente na região litorânea brasileira (restringindo-se aos refúgios de difícil acesso). (AMADOR, 1997)

A Mata Atlântica, como ressaltado por Lamego (1963), foi uma barreira natural para a conquista do território brasileiro pelos europeus devido às suas características desconhecidas dos povos do "Velho Continente", sendo seu uso inicial relacionado diretamente com o desmatamento para extração de madeiras nobres de elevado valor comercial. A primeira grande intervenção neste domínio florestal começa em meados do século XIX, com a implantação da cultura do café, devido ao seu valor econômico e pelas condições naturais adequadas ao seu cultivo, tendo seus graves impactos descritos por Lamego (1963) e Dean (1996). Nesta unidade a fase do café restringiu-se às baixas encostas, não atingindo as altas encostas da serra.

A fase do café perde sua força na região no final do século XIX e, juntamente com o fim da éscravidão em 1888, a área da bacia sofreu um período de estagnação econômica, com os cafezais sendo substituídos por atividades de pecuária e a paisagem sendo dominada por pastagens. Na ocupação mais atual, a partir da década de 70, grandes desmatamentos ocorreram pela atividade madeireira interessada na produção de carvão e na extração de imbuia para a produção de tamancos. A partir da década de 80, a floresta foi substituída pela agricultura de subsistência como a banana e a mandioca, com baixo nível técnico e sem preocupação com a preservação do solo. (CUNHA, 1995)

Tal unidade, como toda a a bacia, vem sendo extremamente agredida desde a ocupação territorial européia, no período de Conquista, até os grandes impactos contemporâneos. Entre os principais impactos antropogênicos, está o próçesso de substituição da mata original, denominado de fragmentação florestal, que é resp̣onsável por mudanças no habitat original, trazendo consequiências irreversíveis, como a extinção de espécies, e graves desequilíbrios ambientais (PINTO-COELHO, 2002). Outro processo fundamental para a compreensão da dinâmica paisagística desse hólon são os processos erosivos (ravinas e voçorocas) facilitados naturalmente pelas altas declividades das vertentes e acelerados por atividades antrópicas, como atividades de agricultura intensiva e predatória na baixa encosta, e exploração madeireira para carvão. (CUNHA, 1995) 


\section{Hólon II}

Representado pela unidade morfo-fisiográfica de planalto muito dissecado (figura 1), área de transição entre as unidades montanhosa e de colinas, localiza-se nos interflúvios dos rios São João e Capivari.

Apresenta um clima bastante chuvoso, com precipitação anual média de $2101,2 \mathrm{~mm}$, devido às chuvas orográficas existentes também na base da serra.

A base geológica é a unidade metamórfica do Complexo do Litoral Fluminense, abordado anteriormente.

A unidade morfo-fisiográfica de planalto muito dissecado, com altitudes variando entre $100 \mathrm{~m}$, a E, e $908 \mathrm{~m}$, a W, na Serra do Sambê, tem encostas íngremes, apresentando declividades superiores a $45 \%$ com ombreiras mais alargadas e setores de encosta mais suaves com declividades entre 6 e $20 \%$, fortemente dissecadas com interflúvios de geometria côncava a convexa e vales simétricos, na maioria de fundos côncavos, e com boa competência transportadora de sedimentos. Apresenta traçado da rede de drenagem com padrão dominante sub-dentrítico, com ramificações em maior número e de pequena extensão, refletindo a presença de um regolito espesso. Devido à interligação de fatores como um espesso manto de intemperismo, solos (baixa fertilidade e permeabilidade), clima (intenso regime de chuvas ao longo do ano) e pressões antrópicas (expansão da pecuária responsável pelo processo erosivo laminar), tem alta potencialidade erosiva com a predominância de processos de rastejamento e voçorocamento.

A vegetação segue o padrão visto no hólon anterior, com a predominância da Floresta Pluvial baixo montana, estando extremamente degradada devido às atividades antrópicas ao longo da história com a predominância de áreas com vegetação pioneira e de capoeiras com estágios de sucessão secundários.

A dinâmica sócio-histórica de tal unidade segue o padrão do hélon anterior, com a presença da cultura do café trazendo uma ocupação mais efetiva após a fase de conquista baseada na exploração madeireira. Após o declínio de tal atividade, no começo do século XX, as lavouras de café são substituídas por pastagens e pela atividade pecuária. A partir de 1960-70, a área passa a sofrer os efeitos da urbanização, principalmente com a construção da BR-101 que corta tal unìdàdé e apresenta grande número de deslizamentos no trecho entre Rio Bonito e Silva Jardim. A principal atividade na área é a pecuária extensiva, conjuntamente à atividades agrícolas.

Os impactos antropogênicos em tal área se referem às atividades históricas, promotoras de grande desmatamento e processos erosivos, predominando processos de ravinamento e rastejamento facilitados pelo pisoteio do gado. 


\section{Hólon III}

Apresenta como área core a unidade morfo-fisiográfica de colinas de tipo meia laranja (figura 1), com zonas de contato ou transição entre o relevo montanhoso, o planalto muito dissecado e o domínio fluvial e litorâneo à jusante do Reservatório de Juturnaíba.

O clima desta unidade apresenta precipitações totais médias anuais entre 1715,9 $\mathrm{mm}$ e $2005,9 \mathrm{~mm}$, apresentando o lugar intermediário nas precipitações entre as unidades da bacia.

A geologia de tal hólon corresponde na sua maior parte à unidade metamórfica do Complexo do Litoral Fluminense, abordada anteriormente.

Em sua geomorfologia, apresenta duas unidades morfo-fisiográficas de características colinosas: colinas do tipo meia laranja e colinas pouco dissecadas. A unidade morfo-fisiográfica de colinas do tipo meia laranja ocorre nos divisores meridionais e nos interflúvios dos rios Capivari e Bacaxá, no médio vale do rio São João e a jusante da lagoa de Juturnaíba. Caracteriza-se por uma topografia mais rebaixada, com altitudes até $100 \mathrm{~m}$, e níveis topográficos escalonados de 100-80 m, 80-60 m e 60-40 m; com "[...] vertentes simétricas, de geometria côncavo-convexas, por vezes com topo convexo alongado, inseridas na planície aluvial e intercaladas por vales pouco alargados e de fundo plano" (CUNHA, 1995, p.113), além de declives acima de $45 \%$ nas encostas íngremes e inferiores a $6 \%$ nas planícies e terraços aluviais. A dissecação topográfica pela erosão fluvial não é forte, assumindo um padrão de drenagem dentrítico baseado no espesso regolito, formado pela resistência dos granitos e gnaisses aos processos erosivos.

A unidade de colinas pouco dissecadas encontra-se na parte sudeste desse hólon, correspondente a menor unidade morfo-fisiográfica da bacia, com níveis altimétricos entre $50-60 \mathrm{~m}$ e $30-40 \mathrm{~m}$, com declives entre 1 e $6 \%$, tendo forma de colinas alongadas, de topos tabulares e vertentes suaves. Os processos erosivos não são fortes devido à natureza ondulada do relevo que facilita a infiltração da água, com o clima também favorecendo tal fato. Os solos (podzólico vermelho-amarelo) são de baixa fertilidade e susceptíveis aos processos erosivos, tendo seu uso pela cultura de laranja.

Um dos principais processos morfoesculturais encontrado nesse setor se refere ao processo de arredondamento da paisagem do domínio morfoclimátíco de "mares de morros", chamado de mamelonização, com mecanismos de biosıasia. Tal processo conjuga-se, devido às oscilações climáticas ao longo do tempo (especialmente no quaternário), com processos de pedimentação, fenômeno oposto ao da mamelonização, representando um processo resistático de erosão generalizada, ao fim do qual a região sofre aplainamentos laterais restritos por pedimentação. (AB'SÁBER, 1973).

A Floresta Atlântica Pluvial baixo montana se apresenta atualmente neste hólon restrita à formações secundárias no topo das elevações, devido ao desmatamento 
histórico responsável pela grande fragmentação florestal. Quanto à fauna desse ecossistema, o representante que se tornou mais ilustre é o mico-leão-dourado (Leontopithecus rosalia rosalia) que conjuntamente à preguiça-de-coleira (Bradypus torquatus) são espécies endêmicas deste tipo de floresta, estão ameaçadas de extinção e são preservadas nas reservas biológicas de Poço das Antas e União. (RIZZINI et alli, 1991; CUNHA, 1995)

A ocupação humana original da área segue as características descritas no hólon anterior. $\mathrm{O}$ processo de colonização se fez mais presente nesta área com a cultura do café e da cana-de açúcar na parte de planície e na zona ondulada das colinas, sendo diretamente influenciada pelo transporte fluvial da produção até o litoral. Esta função foi extinta com a criação do ramal da Estrada de Ferro da Leopoldina (1888), que passou a servir às zonas de cultivo de café e açúcar e de extração de madeira, passando junto à lagoa de Juturnaíba. Com o declínio destas atividades a partir da lei de Abolição dos Escravos, as antigas áreas de cultivo passaram a ser ocupadas pela criação extensiva de gado e o cultivo de cítricos, dominando a paisagem deste hólon no início do século XX.

A partir dos anos 70, ocorre a difusão da "Revolução Verde" impulsionada pelas indústrias de máquinas e implementos grícolas, e de agrotóxicos e defensivos químicos, acarretando uma pressão ainda maior aos solos que, conjugado a novos fatores como a poluição química, trouxe uma drástica amplificaçãọ dos problemas ambientais ligados à atividade agrícola (GONÇALVES, 2002).

A urbanização na área apresenta duas sedes municipais, Silva Jardim e Casimiro de Abreu, ambás com pouco mais de 10 mil habitantes. Os principais problemas ambientais em tais sítios urbanos se referem à poluição ambiental sob diversas formas: lixões, aterros sanitários, resíduos sólidos, despejo de esgoto "in natura", e outros.

Os impactos antropogênicos nas condições paisagísticas originais de tal unidade provém das atividades históricas de desmatamento, a pecuária intensiva, atividades agrícolas degradantes (com uso de agrotóxicos e sem práticas de agroecologia).

\section{Hólon IV}

Compreende a unidade morfo-fisiográfica dos vales alargados (figura 1), correspondendo ao setor aluvial dos rios São João, Bacaxá e Capivari, podendo ser subdividida entre o vale médio do rio São João a montante do reservatório de Juturnaíba, os vales dos rios Capivari e Bacaxá, e baixo vale do rio São João, a jusante do reservatório.

O clima varia entre o setor de tal unidade considerado, tendo o baixo vale do rio São João um clima mais seco, em virtude da proximidade do litoral, e os outros setores a montante climas mais úmidos. 
A geologia apresenta predominância de unidades sedimentares quaternárias com depósitos fluviais e colúvio-alúviais constituídos por areias médias a grosseiras, feldspáticas e pouco selecionadas; os depósitos aluviais dos terraços de várzea apresentam material argilo-arenoso com ou sem matéria orgânica. Ocorre ainda a presença de depósitos recentes de carvão relacionados aos ambientes de sedimentação alagadiços e lagunares responsáveis pela formação de turfeiras, como na parte norte da lagoa de Juturnaíba junto à Reserva Biológica de Poço das Antas.

A unidade morfo-fisiográfica de vales alargados representa os terraços e as planícies de inundação dos rios São João, Capivari e Bacaxá, com declives dominantes inferiores a $1 \%$, com exceção do alto curso e dos cursos nas proximidades de colina meia laranja, onde atingem $6 \%$ e altitudes de até $23 \mathrm{~m}$, no alto curso, e de 5-6 m no baixo vale do rio São João. Presença de rios divagantes com meandros abandonados, refletem as mudanças periódicas no regime de escoamento; além de corresponder às áreas de acumulação de sedimentos, oriundos dos altos cursos, em margens convexas e nos bancos marginais dos leitos. As características climáticas mais secas e a topografia horizontal tornam a potencialidade erosiva baixa em solos aluviais e hidromórficos, originários da deposição de sedimentos aluviais ou colúvio-aluviais quaternários. A área sofre a influência maior das atividades de pastoreio e seus processos relacionados, além da degradação da mata ciliar que protege o solo das margens dos rios e as vegetações adaptadas aos pântanos e brejos.

Os ecossistemas principais de tal unidade são a mata ciliar e os ambientes lacustres e pantanosos, sendo esses meios adaptações da Mata Atlântica às condições ambientais locais mais úmidas, semelhante ao domínio dos brejos. A principal descrição a respeito da mata ciliar do rio São João identificou nesta unidade geossistêmica boas condições de preservação na área de nascentes. A mata ciliar na área dos vales médios apresenta comunidades vegetais adaptadas às condições ambientais de terrenos inundados ou brejos apresentando-se preservada em alguns trechos. O meio lacustre é composto de ictiofauna rica, espécies como lontra (Lutra) e capivara (Hydrochoeris), e uma série de comunidades de algas, plânctons e organismos microscópicos. (CUNHA, 1995)

Entre as principais características de sua ocupação está a grande perturbação de cunho antrópico ocasionada pelas obras de engenharia como a retificação de canais e a construção do reservatório de Juturnaíba, principalmente a partir da década de 1970. As grandes transformações antrópicas no ambiente vieram a partir de meados do século XX, com as sucessivas retificações nos cursos dos rios São João, Bacaxá e Capivari por de obras de canalização, através de alargamento e aprofundamento de seus leitos, com o objetivo de sanear a planície de inundação e facilitar a construção da BR-101. O baixo vale do rio São João apresenta atividades agrícolas, como a cana-de-açúcar e o arroz, sem métodos de manejo de tais agroecossistemas.

$\mathrm{Na}$ década de 1970, o principal projeto social na área foi implementado pelo governo militar com a barragem de Juturnaíba, projetada para o abastecimento de 
água da região dos Lagos, ao controle das cheias e aos projetos de irrigação para a produção de hortifrutigranjeiros no setor do rio São João a jusante. Tal barragem foi implementada sem nenhuma legislação que obrigasse o estudo dos impactos ambientais do projeto.

A barragem e o plano de valorização do vale do São João tiveram como resposta a criação, em 1981, da Reserva Biológica de Poço das Antas que visa proteger o hábitat original do mico-leão-dourado (Leontopithecus rosalia rosalia), animal com risco de extinção, porém tal reserva apresenta problemas com incêndios devido aos impactos de emersão das turfeiras pelas obras de engenharia citadas.

Os impactos principais decorrem das ações de represamento, com graves consequiências geomorfológicas, hidrológicas e bióticas potenciais e identificadas por Cunha (1995) em variados setores da bacia e interligados entre si, podendo influir em áreas de outras unidades geossistêmicas. No reservatório e periferia ocorreu, entre outros impactos, o afogamento de espécies vegetais e animais, a formação de ilhas de gramíneas flutuantes, processos de assoreamento e eutrofização, mudanças nas comunidades aquáticas, a destruição de um ou mais biótopos pela ascenção do lençol freático e impactos micro-climáticos.

Os impactos geomorfológicos da construção do reservatório de Juturnaíba são bastante graves e influem tal unidade geossistêmica em dois setores. A montante do reservatório, o aumento do nível de base local acentuou os processos de assoreamento (favorecendo as atividades de extração de areias no médio vale do rio São João), o que ocasiona a formação de novas áreas de inundação nas planícies durante as cheias. A jusante da barragem, os impactos potenciais são o entalhe no leito do rio São João, processos de erosão e de deposição nas margens fundo do leito, a retomada erosiva (entalhe) dos seus leitos e alterações sedimentares no fundo e nas margens dos canais; além de mudanças na dinâmica da foz. A construção do reservatório de Juturnaíba também traz graves conseqüências ecológicas. A montante do reservatório, ocorrem modificações na vegetação e fauna aquáticas e ciliares da planície de inundação, com um alargamento dos biótopos palustres. A jusante da barragem, ocorrem modificações na vegetação ciliar e nas espécies aquáticas; além da emersão das turfeiras da mata ciliar na margem esquerda do rio São João, ocasionando o aumento dos incêndios e de suas conseqüências. (CUNHA, 1995)

Os impactos antropogênicos causados pelas obras de retificação de canais podem ser divididos por setor. No setor do canal modificado, os principais efeitos são: a modificação do padrão de drenagem meândrico para uma rede de canais quase reta, a alteração na morfologia dos canais, a erosão nos afluentes, o aumento do gradiente repercutindo na capacidade e competência de transporte da carga sólida. A jusante da retificação, os impactos são o aumento da carga sólida e assoreamento, a erosão no canal, e modificações potenciais na dinâmica da foz. Nas planícies de inundação, os trechos abandonados do leito formam bacias de decantação que, posteriormente, foram transformados totalmente com a implantação de ativi- 
dades agrícolas, principalmente na planície de inundação à jusante do reservatório de Juturnaíba. (CUNHA, 1995)

Outra atividade bastante impactante é a extração de areias , Mello et alli (2003) estudam a mineração de areia no setor areeiro de Silva Jardim (a montante da barragem), mostrando algumas mudanças na dinâmica fluvial através de seções transversais e da análise granulométrica da areia. Porém, os autores não avançam numa perspectiva mais integrada dos impactos da extração de. areias, chegando a considerar a atividade como benéfica para o rio, se ordenada e regulada; esquecendo-se do grave desequilíbrio ecológico relacionado com tais atividades. Além do que os benefícios para o sistema fluvial seriam a manutenção das retificações de seu canal, impedindo a formação de soleiras e depressões, que são a manifestação da renaturalização do canal e o primeiro estágio no retorno às condições meandrantes.

\section{Hólon V}

Corresponde à região flúvio-marinha da bacia (figura 1), sendo a zona de armazenamento de sedimentos que se relaciona à zona de desembocadura e o baixo curso do rio São João.

As características climáticas apontam a existência de um clima mais seco, com os mais baixos valores da precipitação anual, entre 1090,3 e 1177,8 mm. A potencialidade erosiva das precipitações é fraca em tal hólon, refletindo as condições mais secas ocasionadas pelo fenômeno da ressurgência de correntes frias nesta parte do litoral brasileiro.

A geologia desta área é dominada por unidades sedimentares compostas de sedimentos flúvio-marinhos que formam as restingas, com idade provável do Pleistoceno Inferior e contribuição direta na sua formação das oscilações climáticas e do nível do mar do Quaternário. Seus sedimentos variam entre areias finas a medias, argilas turfosas e argilas orgânicas finas.

A geomorfologia é representada pela unidade morfo-fisiográfica do litoral inclui a planície costeira e os cordões de restinga, tendo uma topografia quase horizontal na desembocadura do rio São João, com declividade de 1 a $6 \%$, onde se desenvolve o mangue sobre solo glei húmico salino, com extensão de até $15 \mathrm{~km}$ para o interior, que é o limite das águas salobras. Destaca-se a presença da antiga praia, os feixes de restinga e os deltas fósseis, com o antigo arco de praia terminando em pequenas falésias mortas. Os principais processos erosivos e deposicionais, nesta unidade, são relacionados ao remodelado da praia atual. (CUNHA, 1995)

Sant'Anna (1975) analisou a geomorfologia desta área litorânea, encontrando quatro unidades relacionadas. A baixada aluvial marinha, caracterizada por cordões litorâneos arenosos fruto do poder construtivo do oceano e dos ventos que contribuíram para a retificação desse trecho do litoral brasileiro, com cobertura de vegetação xeromórfica nas partes mais elevadas e vegetação higrófila nos interflú- 
vios, além da presença de sambaquis. As baixadas aluviais fluviais correspondem ao domínio dos brejos, nos vales alargados, com pequenos morrotes que se estendem até a área da barragem de Juturnaíba. As pequenas elevações cristalinas são resultado direto dos processos fisiográficos e ecológicos do Quaternário. A última unidade, o Morro São João tem o caráter de morro testemunho que poderia ter sido modelado sob um clima mais úmido (monadknock).

$\mathrm{O}$ ecossistema de tal hólon apresenta duas formações principais: a restinga e o mangue, sendo ecossistemas complementares das matas atlânticas. A unidade biótica da restinga corresponde a uma pequena faixa arenosa, com a presença de antigos cordões litorâneos e psabiomas com vegetação psamófila, adaptada aos solos arenosos, e réstias de vegetação halófila-psamófila, em meios arenosos ricos em sal. Apresenta poucos remanescentes devido à ação do fogo, da expansão urbana e da caça; entre os quais, na flora, bromélias, vegetação herbácea, cipós, coqueiros; e na fauna, de cachorros do mato, furões, gatos do mato, caranguejos maria-farinha, gaivotas, estando o jacaré-de-papo-amarelo extinto na área. (CUNHA, 1995; AB'SÁBER, 2001a)

A unidade biótica de mangue (helobiomas) restringe-se aos meios salobros perto da desembocadura do rio São João "[...] em faixas de solo lodoso sujeito à salinidade emitida pelo ingresso das marés" (AB'SÁBER, 2001a, p.24), encontrando-se bastante degradada, inclusive com a transição do mangue para a restinga tendo sido destruída na década de 70 . Apresenta vegetação de mangue vermelho, preto e branco, o algodão da praia e a samambaia-do-brejo além de fauna com caranguejos, siris e guaxinins; sendo os problemas ambientais mais graves encontrados nesse ecossistema a expansão urbana, o despejo de esgoto e de resíduos sólidos (CUNHA, 1995; PRIMO; VÖLCKER, 2003).

A ocupação humana inicial da área tem como testemunhos os sambaquis formados aproximadamente 8.000 anos A.P. por povos de caçadores e coletores (em especial dos mariscos que formam os sambaquis) com conhecimentos rudimentares relativos ao uso de pedras e outros utensílios naturais. Quanto ao domínio dos tupi-guaranis e tapuias sabe-se que o litoral da região de Cabo Frio é considerado o ultimo baluarte, foco de concentração e de resistência dos tupinambás do Rio de Janeiro, praticamente submetidos pelos portugueses entre 1564 e 1568, que só foi conquistado definitivamente em 1574. (AMADOR, 1997; FERNANDES, 1963)

A principal função social dessa área após a chegada dos europeus foi o transporte de produtos agrícolas e madeira provenientes da Serra do Mar (hólon serrano ou I), sendo Barra de São João um dos principais portos fluminenses na época do cultivo do café.O litoral apresentava na década de 1950 a pesca artesanal na barra do rio, a exportação do carvão extraído da mata de restinga e do Morro São João e a fabricação de canoas com madeira de lei que serviam as comunidades de pescadores de toda a região de Araruama e Cabo Frio; os loteamentos e a atividade de turismo começam a aparecer na área com a construção da rodovia nessa década (BERNARDES, 1957). A partir dos anos 1960-70, a faixa de restinga foi aprovei- 
tada para a construção da rodovia e a construção de novos loteamentos, decorrentes do processo de urbanização do litoral, com o incremento da atividade turística.

Os impactos antrópicos nesse hólon são decorrentes da urbanização e do processo de abertura de estradas, loteamentos, incremento de atividades turísticas, etc. Conjuntamente a esses, ocorre ainda a possibilidade da área sofrer impactos de ações ocorrentes nos outros hólons da bacia, como a barragem de Juturnaíba e as obras de retificação de canais, entre outras ações como desmatamentos, urbanização, etc. O principal impacto registrado na área é de cunho biótico, envolvendo o desmatamento e devastação das matas de restingas extremamente raras e importantes. Outros impactos referentes à urbanização são a poluição ambiental com resíduos físicos e químicos impactantes nas condições ambientais dos ecossistemas da área. Os impactos das obras de engenharia na bacia podem afetar o regime da foz, a salinidade das águas e outras mudanças potenciais.

\section{Propostas de Gestão Ambiental}

A política e legislação de gestão ou gerenciamento de bacias hidrográficas no Brasil sofreu grandes transformações recentemente, reflexo da conscientização ambiental emergente. Para tal, a atual legislação federal sobre recursos hídricos (Lei das Águas, $n^{\circ}$ 9.433/97) instituiu a bacia hidrográfica como unidade físico-territorial de planejamento e gestão ambientais, através do reconhecimento da água como um bem econômico e dos conflitos entre os múltiplos interesses e usos dos recursos hídricos; além da instituição de um modelo de gestão descentralizado e participativo (CUNHA; COELHO, 2003). O modelo de gestão ultimamente adotado é o modelo sistêmico de integração participativa que se caracteriza pelo planejamento estratégico por bacia hidrográfica, a tomada de decisão através de deliberações multilaterais e descentralizadas e o estabelecimento de instrumentos legais e financeiros (CAMPOS, 2003).

A instituição da bacia do rio São João como APA leva à busca de modelos participativos para o planejamento e a gestão ambientais, tendo o Comitê das Bacias Hidrográficas das Lagoas de Araruama e Saquarema e dos Rios São João, Una e Ostras papel fundamental neste processo de conjugação dos interesses da sociedade civil com os projetos para a área (COSTA, 1999).

O hólon I é área fundamental na gestão ambiental da bacia em questão devido à característica de zona de erosão, contribuindo diretamente na carga sólida carregada a jusante o que traz problemas como assoreamento, redução da qualidade das águas, etc. Torna-se necessário um projeto de reflorestamento da área montanhosa de forma planejada: com estudos prévios interdisciplinares que permitam uma recuperação das áreas degradadas e uma continuidade na sucessão das áreas com vegetação secundária, em harmonia com as condições ecossistêmicas presentes nas 
áreas de Floresta Pluvial Atlântica montana ou baixo montana. (AB'SÁBER, 2001b; LIMA; ZAKIA, 2001).

As atividades sociais predatórias devem ser substituídas aos poucos ou reguladas por formas de agricultura ecológica adaptadas aos ecossistemas locais e outras atividades de manejo provenientes da floresta (como o palmito, espécies medicinais, etc.), o que produziria uma interligação fundamental entre seus habitantes e o meio. As áreas com processos erosivos mais acelerados devem ser estudadas com o intuito de encontrar alternativas locais para a recuperação ambiental desses lugares.

A unidade II necessita de novas práticas, diferentes da dominante pecuária extensiva, relacionadas com a recuperação das áreas degradadas e planos de reflorestamento possibilitando a sucessão ecológica e a recuperação florestal. Métodos e técnicas agroecológicas devem ser popularizados na área, em busca de uma produção sustentável. A BR-101 merece especial destaque em relação à contenção e recuperação de encostas causadoras de deslizamentos.

A unidade geossistêmica III mais afetada pela ocupação humana, em especial devido às obras de engenharia como a construção de estradas e o processo de urbanização. As atitudes de reflorestamento, como vistas no hólon anterior, devem ser acompanhadas do estudo e monitoramento sistemático dos impactos causados pelas obras de engenharia e da busca de condições ambientais o mais próximas do original, através de intervenções corretivas.

Os diversos impactos ambientais decorrentes do processo de urbanização devem ser constantemente estudados e monitorados, em vista da qualidade de vida de suas populações atuais e vindouras. Um planejamento holístico e eficiente deve ser contraposto à concepção tradicional de urbanismo (calcada apenas nas estruturas e funções de natureza social), envolvendo todos os atores sociais na construção de um ambiente que propicie a qualidade de vida, através de um metabolismo urbano equilibrado e reciclável, sem esbanjamentos e desperdícios de matéria e energia.

Esta é a área da bacia com maior atividade agropecuária o que representa a necessidade de estudos locais das condições ambientais de tais agroecossistemas para a implantação de métodos e técnicas de cultivo agroecológicos apropriados às características ambientais de tal hólon. A recuperação das áreas com processos erosivos acelerados e com a presença de turfeiras emersas, além da conservação de áreas importantes como as matas ciliares e os corredores ecológicos, são elementos fundamentais para o manejo agroecológico.

A gestão ambiental da unidade IV é relacionada com a busca de um ambiente fluvial equilibrado, envolvendo projetos de recuperação de canais e das matas ciliares. Os impactos ambientais causados pela construção do reservatório de Juturnaíba devem ser monitorados através de estações, em especial dos depósitos e das praias em formação, do assoreamento, das ilhas flutuantes de gramíneas, da qualidade das águas, etc (CUNHA, 1995). Os canais retificados devem passar por processos de recuperação, através da estabilização do desenvolvimento de hábitats e da colonização a uma taxa mais veloz que a dos processos naturais físicos e eco- 
lógicos, estando associadas à estudos do sistema sedimentológico fluvial e a uma gestão ambiental que garanta a criação de um ambiente fluvial sustentável (CUNHA, 2003). As áreas que passaram por extração de areias devem ser recuperadas através de estudos ambientais integrados, além de programas de educação e conscientização ambiental voltados para as comunidades em questão.

O gerenciamento costeiro é uma atividade de planejamento instituída pelos meios governamentais desde 1988 que permite um uso sustentável dos recursos naturais e do patrimônio étnico, histórico e cultural do litoral brasileiro, em benefício de suas populações. Entre as principais atividades desenvolvidas estão a delimitação das zonas costeiras; o inventário do patrimônio natural, sócio-econômico e cultural; e o macrozoneamento ambiental, sendo fundamental a participação das populações envolvidas. (DIEGUES, 2001)

O planejamento e gestão ambiental devem estar relacionados com a preservação e reintrodução de espécies nativas das restingas e dos manguezais; a busca de um modelo de urbanização não-predatório; o uso da atividade turística de forma ecologicamente correta; a preocupação constante com a qualidade das águas fluviais e oceânicas e de seus ecossistemas; estudos voltados para o planejamento costeiro da área de forma interdisciplinar e integrada; entre outras ações integradas à participação das comunidades locais a fim de realizar a construção de um ambiente costeiro sustentável.

\section{Conclusão}

As complexas relações entre a sociedade e a natureza podem ter uma grande compreensão sob o olhar geossistêmico de cunho integrador, que não assuma uma posição determinista ou reducionista. $\mathrm{O}$ uso das concepções de geossistemas e de fisiologia da paisagem permite uma avaliação de cunho integrador das condições ambientais da área em questão, podendo ser uma importante contribuição ao planejamento e à gestão ambientais.

Os estudos e monitoramentos ambientais da bacia devem buscar as inter-relações entre as diversas variáveis, por mais especializados que sejam, buscando a inter e transdisciplinaridade na pesquisa ambiental. A dinâmica do ambiente natural se mostrou, além da interconexão entre seus elementos, extremamente influenciada pela dinâmica social em seu processo de ocupação histórica. As interações entre as variáveis do ambiente biofísico e social são os elementos responsáveis pelos processos e pela dinâmica da paisagem. Assim, pode-se destacar que o elemento antrópico após o processo de colonização assumiu um caráter fundamental na dinâmica ambiental da área, transformando totalmente características naturais (caso do desmatamento histórico e das obras de engenharia) e acelerando profundamente processos naturais resistáticos, como a erosão acelerada. 
As ações práticas do planejamento e da gestão ambientais devem ser caracterizadas pelo princípio da descentralização da tomada de decisões com a participação direta das comunidades locais, que devem ser apoiadas pelas instituições governamentais e da sociedade civil na busca de uma auto-sustentabilidade. Outro fator fundamental para o sucesso da gestão ambiental planejada é a mudança da percepção ambiental das populações da bacia sob o paradigma dominante, através de programas de educação e conscientização ambiental que posssibilitem o entendimento de forma holística e complexa das questões ambientais. $\mathrm{O}$ resgate dos valores culturais e étnicos, aliado à busca de novos modos de percepção ambiental adequados à sustentabilidade, são fatores que podem influenciar diretamente na melhoria da qualidade ambiental.

Como visto, o equilíbrio dinâmico da fisiologia da paisagem funda-se nas relações entre os elementos do geossistema, cabendo ao homem e seu modelo sóciocultural a responsabilidade por grande parte dos problemas ambientais e também pela defesa e a busca de condições ambientais mais justas; onde o ambiente não é visto como um objeto de produção ou um território de dominação, mas como parte indissolúvel do geossistema vivo planetário.

A melhoria da qualidade de vida e a busca de liberdade e igualdade social passam pelo reconhecimento por todos nós e nossas instituições da responsabilidade que temos pelo uso harmonioso e sustentável da paisagem e seus recursos físicos, ecológicos e culturais, herdados durante a longa jornada de Gaia na constituição da vida e seu ambiente intrínseco. O destino de Gaia nessa jornada está em nossas mãos e, apesar de todos problemas e da complexidade dos mesmos, são necessárias transformações ou revoluções permanentes em busca de libertar o Homem e a Natureza da dominação humana.

\section{GEOSSISTEMAS E GESTÃO AMBIENTAL NA BACIA HIDROGRÁFICA DO RIO SÃO JOÃO-RJ}

Resumo: Trata o presente artigo de um estudo de caso envolvendo a caracterização dos geossistemas na bacia hidrográfica do rio São João-RJ, relacionado diretamente com uma abordagem complexa e integradora da relação natureza e sociedade, e com as práticas de gestão ambiental em busca de um desenvolvimento sustentável. O principal resultado é a compartimentação espacial em unidades geossistêmicas integrando as variáveis ambientais físicas, ecológicas e sociais. Tais unidades são relacionadas com a busca de estratégias para uma gestão ambiental complexa e holística.

Palavras-chave: geossistemas, fisiologia da paisagem, complexidade, gestão ambiental, desenvolvimento sustentável.

\section{GEOSYSTEMS AND ENVIRONMENTAL MANAGEMENT IN SÃO JOÃO RIVER BASIN}

Abstract: This paper is a study case involving the characterization of the geosystems in São João river basin, related with a complex and integrated view of the relationship between nature and society, and with the actions of environmental management and the search 
for sustainable development. The main result is the spacial compartimentation in geosystemic unities integrating the physical, ecological and social environmental variables. These unities are related with the search of strategies for a complex and holistic environmental management.

Key words: geosystems, landscape physiology, complexity, environmental management, sustainable development.

\section{BIBLIOGRAFIA}

AB’SÁBER, Aziz Nacib. (1966). Domínio dos "mares de morros" no Brasil. Geomorfologia, São Paulo, IGEOG USP, n.2.

. (1969). Um conceito de Geomorfologia a serviço das pesquisas sobre o Quaternário. Geomorfologia, São Paulo, IGEOG USP, n.18.

(1973). A organização natural das paisagens inter e subtropicais brasileiras. Geomorfologia, São Paulo, IGEOG USP, n.41.

. (2001 a). Litoral do Brasil. São Paulo, Metalivros, 288p.

(2001b). O suporte geoecológico das florestas beiradeiras (ciliares).

In: Rodrigues, R.; Leitão Filho, H. F. (eds.). Matas ciliares: conservação e recuperação. São Paulo: Edusp, p.15-26.

(2003). Os domínios da natureza no Brasil: potencialidades paisagísticas. São Paulo: Ateliê Editorial, 159p.

AMADOR, Elmo da Silva. (1997). Baía da Guanabara e ecossistemas periféricos: homem e natureza. Rio de Janeiro: Edição do Autor, 539p.

BERNARDES, Lysia Maria Cavalcanti. (1957). Planície litorânea e zona canavieira do Rio de Janeiro. Rio de Janeiro: Conselho Nacional de Geografia, 248p.

BERTRAND, Georges. (1972). Paisagem e Geografia Física Global: esboço metodológico. Caderno de Ciências da Terra, São Paulo, IGEOG-USP, n.13, 27p.

CAMPOS, Hernani Loebler. (2003). Processo histórico de gestão na bacia hidrográfica do rio Beberibe ( $P E$ ): uma retrospectiva. Rio de Janeiro, Tese (Doutorado em Geografia), Programa de Pós-Graduação em Geografia, Universidade Federal do Rio de Janeiro.

CAPRA, Fritjof. (2003). As conexões ocultas: ciência para uma vida sustentável. $3^{\mathrm{a}}$ ed. São Paulo. 296p.

CASSETI, Valter. (1991). Ambiente e apropriação do relevo. São Paulo: Contexto. CHORLEY, Richard J. (1971). A Geomorfologia e a teoria dos sistemas gerais. Notícia Geomorfológica, Campinas, v.11, n.21, p.3-22.

CHRISTOFOLETTI, Antonio. (2002). Modelagem de sistemas ambientais. $2^{\mathrm{a}}$ reimp. São Paulo: Edgard Blücher, 236p. 
COSTA, Helder. (1999). Subsídios para a gestão dos recursos hídricos das bacias hidrográficas dos rios Macacu, São João, Macaé e Macabu. Rio de Janeiro: SEMA, 280p.

CUNHA, Sandra Baptista da. (1995). Impactos das obras de engenharia sobre o ambiente biofísico da bacia do rio São João. Rio de Janeiro: Edição do autor. (2003). Canais fluviais e a questão ambiental. In: ; GUERRA, A. J. T. (orgs.) A questão ambiental: diferentes abordagens. Rio de Janeiro: Bertrand Brasil, p.219-238.

.(2000) GUERRA, Antonio José Teixeira. Degradação ambiental In: GUERRA, J.T.; CUNHA, S.B. (orgs.). Geomorfologia e meio ambiente. $3^{\mathrm{a}}$ ed. Rio de Janeiro: Bertrand Brasil, p. 337-379.

CUNHA, L. H.; COELHO, M.C.N. (2003). Política e gestão ambiental. In: CUNHA, S. B.; GUERRA, A. J. T. (orgs.). A questão ambiental: diferentes abordagens. Rio de Janeiro: Bertrand Brasil, p.43-79.

DEAN, Warren. (1996). A ferro e fogo: a história e a devastação da Mata Atlântica brasileira. São Paulo: Companhia das Letras, 484p..

DIEGUES, Antonio Carlos. (2001). Ecologia Humana e Planejamento em Áreas Costeiras. $2^{a}$ ed. São Paulo: NUPAUB-USP, 225p.

ERHART, Henri. (1962). Biostasia e resistasia: esboço de uma teoria que considera a pedogênese como um fenômeno geológico. Notícia Geomorfológica. Campinas, n.9-10.

(1966). A teoria bio-resistática e os problemas biogeográficos e paleobiológicos. Notícia Geomorfológica, n.11, p.51-58.

FERNANDES, Florestan. (1963). Organização social dos tupinambá. São Paulo: Difusão Européia do Livro.

FEYERABEND, Paul. (1989). Contra o método: esboço de uma teoria anárquica da teoria do conhecimento. $3^{\mathrm{a}}$ ed., Rio de Janeiro: Francisco Alves, 488p.

FREITAS, Marcos Wellausen Dias de. (2004). Fisiologia da paisagem e geossistemas da bacia hidrográfica do rio São João-RJ: um enfoque complexo. Niterói, Monografia (Graduação em Geografia), Universidade Federal Fluminense, 108p.

FREITAS, Marcos Wellausen Dias de; CUNHA, Sandra Baptista da. (2002). A Geomorfologia, os estudos da complexidade e o desenvolvimento sustentável. Anais VII Encontro do Instituto de Geociências, Niterói: Instituto de Geociências/UFF, p.257-266.

(2003). Fisiologia da paisagem e geossistemas: contribuições metodológicas integradoras do pensamento geográfico. Geouerj-Revista do Departamento de Geografia, Rio de Janeirø:UERJ, núm. esp., em cd-rom.

GONÇALVES, Carlos Walter Porto. (2002). Formação sócio-espacial e questão ambiental no Brasil. In: BECKER, Berta et alli (orgs.). Geografia e meio ambiente no Brasil. $3^{\mathrm{a}}$ ed. São Paulo: Hucitec, p.309-333. 
HACK, John T. (1972). Interpretação da topografia erodida em regiões temperadas úmidas Notícia Geomorfológica, Campinas, ano 12, v.24, p.3-37.

KOESTLER, Arthur. Jano. (1981). São Paulo, Melhoramentos, 326p.

KUHN, Thomas. (1989). A estrutura das revoluções científicas. $3^{\mathrm{a}} \mathrm{ed}$., São Paulo: Perspectiva.

LAMEGO, Alberto Ribeiro. (1963). O homem e a serra. Rio de Janeiro, IBGE, $397 p$.

LIMA, Walter de Paula; ZAKIA, Maria José Brito. (2001). Hidrologia de matas ciliares. In: RODRIGUES, R. R.; LEITÃO FILHO, H. F. (eds.). Matas ciliares: conservação e recuperação. São Paulo: Edusp, p.33-44.

LOVELOCK, James E. (1997). A Terra como um organismo vivo. In: Wilson, E. O. (org.) Biodiversidade. Rio de Janeiro: Nova Fronteira, p.619-623.

MATURANA, Humberto R.; VARELA, Francisco J. (2001). A árvore do conhecimento: as bases biológicas da compreensão humana. São Paulo: Palas Athena, 288p.

MELLO, E. F. et alli. (2003). A mineração de areia no curso médio-superior do rio São João, município de Silva Jardim, RJ: conflitos ambientais e desenvolvimento sustentável. III Seminário Recursos Geológicos, Ambiente e Ordenamento do Território, Vila Real: Universidade de Trás-Os-Montes e Alto Douro, p.71-79.

MONTEIRO, Carlos Augusto de Figueiredo. (1987). Geografia e uso da terra nos trópicos. In: Miranda, Maria do Carmo Tavares de (org.). Ciência para os trópicos: Anais do I Congresso Brasileiro de Tropicologia. Recife, Fundação Joaquim Nabuco, p.43-67.

(1991). Clima e excepcionalismo: conjeturas sobre o desempenho da atmosfera como fenômeno geográfico. Florianópolis, Ed. da UFSC.

. (2001a). William Morris Davis e a teoria geográfica. Revista Brasileira de Geomorfologia, UGB, v.2, n.1, p.1-20.

(2001b). Geossistemas: a história de uma procura. São Paulo, Contexto, 125p.

(2001c). Derivações antropogenéticas dos geossistemas terrestres no Brasil e alterações climáticas: perspectivas urbanas e agrárias ao problema da elaboração de modelos de avaliação. Ra'ega, Curitiba: Ed. UFPR, n.5, p.197226.

MORIN, Edgar. (2002) O método I: a natureza da natureza. Porto Alegre: Sulina, $479 \mathrm{p}$.

; KERN, Anne B. (1995). Terra-Pátria. Porto Alegre: Sulina, 189p.

NUSSENZVEIG, H. Moysés. (1999). Introdução à complexidade. In: (org.)

Complexidade e caos. Rio de Janeiro: Editora UFRJ/COPEA, p.9-26.

PINTO-COELHO, Ricardo Motta. (2002). Fundamentos em ecologia. $1^{\text {a }}$ reimp. rev., Porto Alegre: ARTMED, 252p. 
PRIGOGINE, Ilya; STENGERS, Isabelle. (1991). A nova aliança: metamorfose da ciência. Brasília: Ed. UnB, 247p.

PRIMO, Paulo Bidegain da Silveira; VÖLCKER, Claudio Michael. (2003). Bacias hidrográficas dos rios São João e das Ostras: águas, terras e conservação ambiental. Rio de Janeiro: Consórcio Intermunicipal para Gestão das Bacias Hidrográficas da Região dos Lagos, Rio São João e Zona Costeira, 170p.

RIZZINI, Carlos Toledo; COIMBRA-FILHO, Adelmar F.; HOUAISS, Antônio.(1991). Ecossistemas brasileiros. Rio de Janeiro: Editora Index, 1991, 159p.

RODRIGUES, Cleide. (2001). A teoria geossistêmica e sua contribuição aos estudos geográficos e ambientais. Revista do Departamento de Geografia, São Paulo: FFCHL/USP, n.14, p.69-77.

ROUGERIE, Gabriel; BEROUTCHACHVILI, Nicolas. (1991). Géosystèmes et paysages: bilan et méthodes. Paris: Armand Colin, 302p.

SANT'ANNA, Edna Mascarenhas. (1975). Estudo geomorfológico da área de Barra de São João e Morro de São João. Revista Brasileira de Geografia, IBGE, ano 37, n³, p.3-15.

SCHUMM, S. A.; LICHTY, R. W. (1973). Tempo, espaço e causalidade em Geomorfologia. Notícia Geomorfológica, Campinas, v.13, n.25, p.43-62.

SOCHAVA, Viktor, B. (1978). Por uma teoria de classificação de geossistemas de vida terrestre. Biogeografia, São Paulo, IGEO-USP, n.14, 25p.

WEAVER, John; CLEMENTS, Frederic. (1950). Ecología vegetal. Buenos Aires, Acme Agency, 667p. 